\title{
Valoración tomográfica inicial en pacientes con neumonía por COVID-19 en el Hospital Central de la Fuerza Aérea del Perú: serie de casos
} Initial CT scanning in patients with COVID-19 pneumonia
in the peruvian central air force hospital: a case series

Correspondencia Ursula Cáceres-Bernaola ucaceresb@yahoo.es

Recibido: 19/06/2020 Arbitrado por pares Aprobado: 17/08/2020

Citar como: Cáceres-Bernaola U, Becerra-Núñez C, Mendiví-Tuchía de Tai S, Ravelo-Hernández J, QuispeAyuque E. Valoración tomográfica inicial en pacientes con neumonía por COVID-19 en el Hospital Central de la Fuerza Aérea del Perú: Serie de casos. Acta Med Peru. 2020;37(3):330-5. doi: https://doi. org/10.35663/amp.2020.373.1010
Ursula Cáceres-Bernaola1,2,a, Claudia Becerra-Núñez ${ }^{1,3, a}$, Sabina MendívilTuchía de Tai ${ }^{1,2, b}$, Jorge Ravelo-Hernández ${ }^{1, a, c}$, Edwin Quispe-Ayuque ${ }^{4, d}$

Sección de Medicina Interna, Infectología, Hospital Central de la Fuerza Aérea. Lima, Perú.

Escuela de Medicina, Universidad Científica del Sur. Lima, Perú.

Escuela de Medicina, Universidad de Piura. Piura, Perú.

Sección de Diagnóstico por Imágenes, Hospital Central de la Fuerza Aérea. Lima, Perú.

Médico internista, ${ }^{\mathrm{b}}$ médico especialista en enfermedades infecciosas y tropicales, ${ }^{\mathrm{C}}$ médico reumatólogo, ${ }^{\mathrm{d}}$ médico radiólogo

\section{RESUMEN}

Se presentan nueve casos de pacientes con COVID-19, que desarrollaron neumonía por el SARS-CoV-2, atendidos en el Hospital Central de la Fuerza Aérea del Perú, con diferentes manifestaciones clínicas, factores de riesgo y evolución; así como la descripción de los hallazgos en la tomografía computarizada de tórax (TCT), empleando un score de severidad tomográfico al ingreso hospitalario. La puntuación se basó en el porcentaje de afectación que tenía cada lóbulo pulmonar y permitió valorar el diagnóstico clínico de neumonía según su severidad, incluso antes que las pruebas moleculares y serológicas dieran positivo en algunos de los casos presentados.

Palabras clave: COVID-19; Coronavirus; Tomografia; Manifestaciones clínicas (fuente: DeCS BIREME).

\section{ABSTRACT}

We present nine cases of COVID-19 patients that developed pneumonia caused by SARSCov-2 who were seen in the Peruvian Central Air Force Hospital and showed different clinical features, risk factors, and outcomes. Findings of their thorax CT scans are described using a tomographic score that was applied on admission. Points assigned were based on the percentage of involvement on each pulmonary lobe and this allowed us to determine a clinical diagnosis of pneumonia according to its severity, even before having positive results in molecular and serological tests for some of these patients.

Keywords: COVID-19; Coronavirus; Tomography; Signs and symptoms (source: MeSH NLM). 


\section{INTRODUCCIÓN}

La presentación clínica de la infección por SARS-CoV-2 va desde asintomáticos hasta formas graves; un $81 \%$ desarrollaría un cuadro leve y el resto cuadros severos o críticos ${ }^{[1]}$. En Lima, la tasa de letalidad alcanza $1,81 \%$ y a nivel nacional, alrededor de $12 \%$ de los hospitalizados presentó evolución desfavorable, siendo la obesidad y la edad mayor de 60 años las condiciones que determinaron mayor riesgo de morir por COVID-19, entre otras (enfermedades renal y pulmonar crónicas, las hepatopatías, enfermedades cardiovasculares y neurológicas, diabetes y cáncer) ${ }^{[2]}$.

La tomografía computarizada del tórax (TCT) es útil para el diagnóstico de neumonía por COVID-19, dada su alta sensibilidad $(97-98 \%)^{[3,4]}$; aunque, investigaciones previas reportan una baja especificidad (25\%); con un valor predictivo positivo de $65 \%$ y un valor predictivo negativo de $83 \%$ frente a la prueba molecular (PM) que detecta al SARS-CoV-2 por reacción de cadena de polimerasa ${ }^{[4]}$. Lo que indica que, en algunos pacientes con PM negativa al inicio, presentan antes imágenes típicas en la $\mathrm{TCT}^{[4,5]}$.

Los signos más frecuentemente encontrados en la TCT son: patrón en vidrio deslustrado multifocal, bilateral, periférico e irregular; áreas de consolidación principalmente alrededor de los haces broncovasculares y espacio subpleural; patrón en empedrado desordenado (crazy paving), engrosamiento de la pared bronquial, bronquiectasias de tracción, dilatación vascular, bandas subpluerales, distorsión de la arquitectura pulmonar entre otras ${ }^{[4,6]}$.

Para medir el grado de afección pulmonar mediante TCT, puede emplearse el "puntaje de severidad total» (Total Severity Score: TSS) ${ }^{[7]}$, el cual nos da una aproximación de la extensión del pulmón afectado inicialmente. Se obtiene calculando el porcentaje aproximado de compromiso de cada uno de los cinco lóbulos pulmonares, que dará una determinada puntuación. Si hay $0 \%$ de afección se puntúa como 0 , si hay una afección entre $1 \%$ al $25 \%$ se puntúa como 1 , si hay una afección entre el $26 \%$ al $50 \%$ se puntúa como 2, si hay una afección entre el $51 \%$ al $75 \%$ se puntúa como 3 y finalmente si hay una afección entre el $76 \%$ al $100 \%$ se puntúa como 4 . El TSS se alcanza sumando los cinco puntajes de los lóbulos (rango de puntajes posibles de 0 a 20) ${ }^{[7,8]}$.

La TCT en pacientes diagnosticados con COVID-19, ha descrito alteraciones pulmonares al inicio, durante la progresión y recuperación de la enfermedad del paciente ${ }^{[9]}$, lo que resulta importante para valorar el curso de la misma, incluso tomando en cuenta el factor predictor de mortalidad, que reportan algunos estudios incluyendo al TSS ${ }^{[10,11]}$, y que serviría para priorizar aquellos pacientes con mayor compromiso pulmonar y se beneficien de un tratamiento más agresivo y oportuno ${ }^{[11]}$.

Presentamos nueve casos confirmados de COVID -19 en un momento de la hospitalización, con el objetivo de dar a conocer sus manifestaciones clínicas, factores de riesgo y evolución de una forma de neumonía (leve moderada o severa), realizando la valoración tomográfica inicial por el TSS al momento del ingreso hospitalario, coadyuvando al manejo de los pacientes.

\section{REPORTE DE CASOS}

\section{Caso 1}

Mujer de 91 años, con antecedentes de demencia vascular, hipertensión arterial (HTA) y fibrosis pulmonar; portadora de sonda nasogástrica siliconada, hospitalizada en febrero y abril de este año por infección urinaria y neumonía respectivamente. Presentó tres días de tos persistente y disnea. Ingresó con una saturación de oxígeno $\left(\mathrm{SatO}_{2}\right)$ de $88 \%$, con cianosis periférica y desorientación. Al inicio las pruebas serológicas resultaron negativas. Los exámenes de laboratorio mostraron Dímero D elevado, anemia y plaquetopenia. La TCT mostró áreas de consolidación que comprometía gran parte de ambos lóbulos inferiores a predominio izquierdo, así como al lóbulo superior izquierdo y en menor medida al lóbulo medio; y áreas en vidrio deslustrado en los lóbulos superiores y lóbulo medio, además derrame pleural basal izquierdo; TSS: 13. Su prueba molecular (PM) resultó negativa. Presentó inicialmente evolución clínica favorable. Después de 2 semanas desmejoró, pese a recibir ceftazidima, enoxaparina, hidroxicloroquina, metilprednisolona. Segunda PM positiva en el día 21 de hospitalización. Falleció al día 29 de admisión.

\section{Caso 2}

Mujer de 68 años, con antecedentes de HTA e hipotiroidismo. Presentó siete días de tos, fiebre, malestar general, escalofríos, vómitos y diarrea. Resultó con PM y serológica positivas. Los exámenes mostraron linfopenia moderada, $\mathrm{PaFiO}_{2}$ menor a 300 y dímero $D$, ferritina, transaminasas y proteína $C$ reactiva (PCR) elevados. La TCT mostró áreas en vidrio deslustrado, algunos de estos de forma redondeada y otros irregulares, que afectaba segmentariamente a todos los lóbulos pulmonares; TSS: 10. Recibió metilprednisolona ( $2 \mathrm{mg} / \mathrm{Kg} / \mathrm{día}$ ), enoxaparina y antibióticos de amplio espectro. Evolucionó desfavorablemente, falleciendo al sexto día de hospitalización.

\section{Caso 3}

Varón de 94 años con antecedente de HTA, estenosis aórtica leve, cáncer de próstata y fibrilación auricular. Presentó 7 días de dorso-lumbalgia y dolor torácico. Su PM y serológicas negativas al ingreso. Hospitalizado por hallazgos tomográficos, que mostraron áreas de consolidación segmentaria en las porciones basales de todos los lóbulos pulmonares a predominio de los lóbulos inferiores, así como algunas áreas en vidrio deslustrado en mismas regiones (TSS: 8); y de laboratorio: linfopenia severa y PCR elevado. Su evolución fue tórpida, cursando con anemia severa. Al octavo día, indicación de manejo intensivo, pero familiares no consintieron. El tratamiento recibido incluyó antibióticos, transfusión sanguínea y enoxaparina. Falleció tras doce días de hospitalización.

\section{Caso 4}

Varón de 46 años, sin antecedentes. Presentó siete días de fiebre, odinofagia, cefalea e hiporexia. Resultó con PM y serológica 

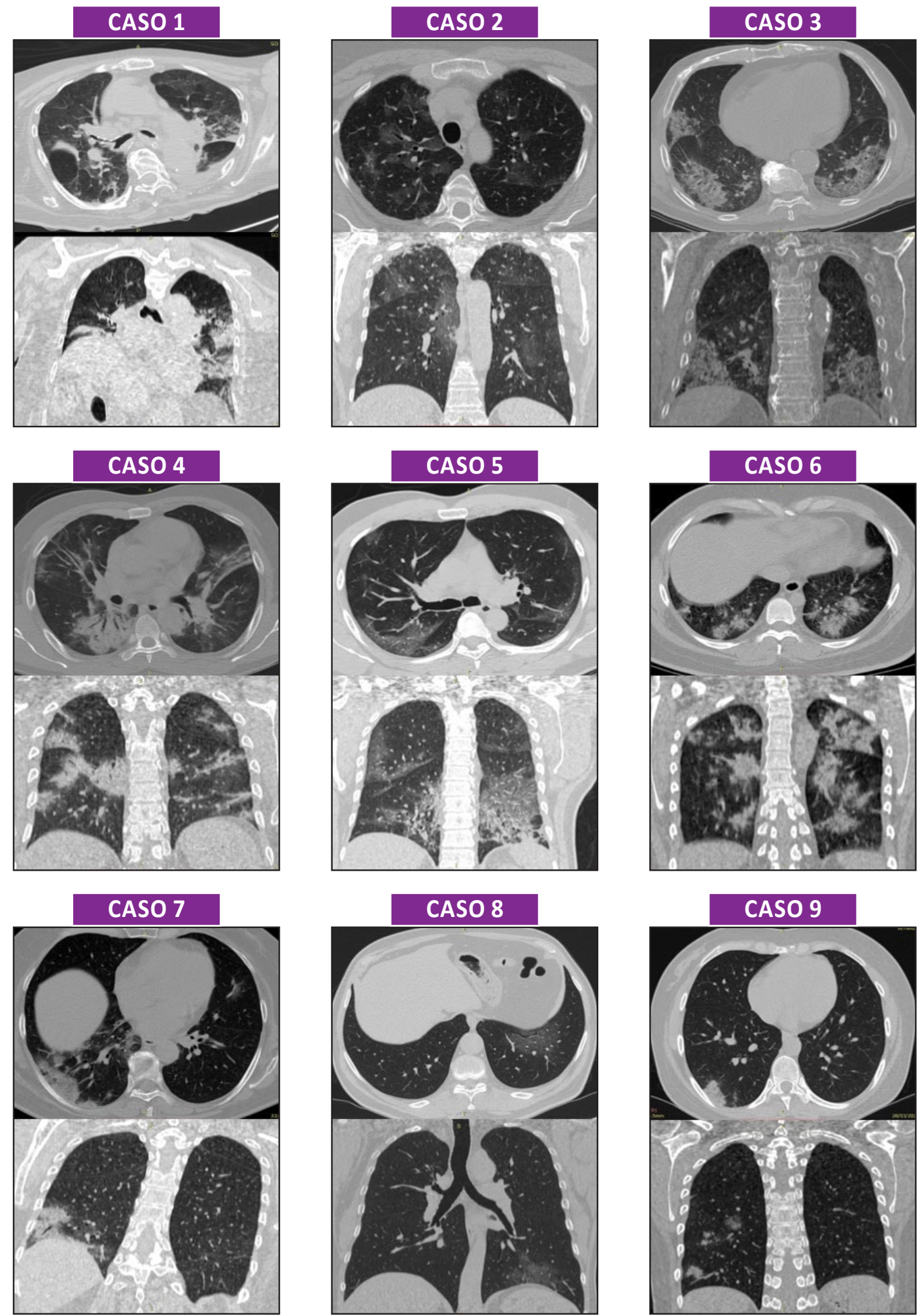

Figura 1. Muestra imágenes de la TCT en axial y coronal. Caso 1 TCT con tenues áreas en vidrio deslustrado bilaterales con área de consolidación en pulmón izquierdo, hay elevación del diafragma y atelectasia basal derecha. Caso 2 TCT con múltiples áreas en vidrio deslustrado centrales y periféricas, algunas adyacentes a las cisuras. Caso 3 TCT con áreas de consolidación que compromete ambas bases pulmonares. Caso 4 TCT con áreas de consolidación con predominio del pulmón derecho y algunas zonas con patrón en vidrio deslustrado bilaterales. Caso 5 TCT con áreas en vidrio deslustrado en regiones sub pleurales con predominio de las bases pulmonares. Caso 6 TCT con áreas de consolidación redondeada centrales y periféricas bilaterales. Caso 7 TCT con áreas de consolidación en base pulmonar derecha y tenues áreas en vidrio deslustrado bilaterales. Caso 8 TCT con área en vidrio deslustrado en base pulmonar izquierda. Caso 9 TCT con área de consolidación bien circunscrita en región subpleural y basal derecha. 
positivas. Al ingreso tuvo $\mathrm{SatO}_{2} 96 \%$ con $\mathrm{FiO}_{2}$ 0,21. Presentó leucocitosis, linfopenia y PCR elevada. Su TCT evidenció áreas de consolidación que comprometía a todos los lóbulos pulmonares, en forma parcheada; las cuales se acompañan de áreas en vidrio deslustrado adyacente; TSS: 8 . Al día siguiente la $\mathrm{SatO}_{2}$ disminuyó a $92 \%$, ingresando a la unidad de cuidados intensivos (UCI). Recibió tratamiento con meropenem, vancomicina, azitromicina, cloroquina, metilprednisolona y enoxaparina. $\mathrm{El} \mathrm{PaFiO}_{2}$ llegó a 211, pero no requirió ventilación mecánica. Evolucionó favorablemente, siendo su alta a los 20 días de la admisión.

\section{Caso 5}

Varón de 44 años, personal de salud, con antecedentes de HTA, sobrepeso, dislipidemia mixta, esteatosis hepática e infección por AH1N1 (2012). Presentó 4 días de tos seca, odinofagia, fiebre, fatiga y disnea. Su primera PM fue negativa, siendo hospitalizado con segunda PM positiva. Al ingreso estaba taquipneico y febril. Su TCT mostró áreas en vidrio deslustrado en las regiones sub pleurales de todos los lóbulos pulmonares; así como áreas con patrón de empedrado desordenado, consolidación y dilataciones bronquiales en ambas bases pulmonares; TSS: 8 . Cursó con linfopenia; PCR, transaminasas y dímero D elevados, $\mathrm{PaFiO}_{2}$ menor a 300. Inició tratamiento con hidroxicloroquina, azitromicina, piperacilina/tazobactam y enoxaparina. Al segundo día, $\mathrm{PaFiO}_{2}$ disminuyó a 180 y elevó ferritina, PCR e IL-6. Persistía febril. Inició tocilizumab a $600 \mathrm{mg} \mathrm{EV} \mathrm{c/12h} \mathrm{(2} \mathrm{dosis)} \mathrm{y} \mathrm{rotó}$ antibióticos a meropenem más linezolid, resolvió la fiebre al día siguiente. Recibió metilprednisolona a $2 \mathrm{mg} / \mathrm{Kg} /$ día. Al día 13, mostró mejoría clínica y tomográfica. Alta al día 18 de hospitalización.

\section{Caso 6}

Mujer de 30 años, con antecedentes de síndrome de Down, asma bronquial y obesidad. Presentó 3 días de tos productiva, disnea, fiebre y malestar general. Ingresó con PM positiva. Al examen físico saturaba 92\%, subfebril y polipneica. La TCT reveló áreas de consolidación, en forma parcheada, que comprometía todos los lóbulos pulmonares; TSS: 8. Recibió tratamiento con hidroxicloroquina, azitromicina, enoxaparina, ceftriaxona. Al cuarto día desmejoró, con mayor requerimiento de oxígeno y empeoramiento tomográfico, donde se evidenció mayores áreas de consolidación en lóbulos inferiores. Recibió metilprednisolona ( $2 \mathrm{mg} / \mathrm{Kg} /$ día) con evolución favorable. Se indicó alta médica a los 20 días de hospitalización.

\section{Caso 7}

Mujer de 63 años, ama de casa, con antecedente de diabetes tipo 2 (DM2) no controlada. Presentó 4 días de odinofagia, tos productiva, dificultad respiratoria y dolor torácico. Al examen físico con taquipnea, taquicardia y $\mathrm{SatO}_{2} 94 \%$ con $\mathrm{FiO}_{2} 0,21$. Exámenes de laboratorio mostraron PCR elevada e hiperglicemia. TCT mostró pequeñas áreas en vidrio deslustrado en ambos lóbulos superiores y áreas de consolidación en los lóbulos inferiores a predominio subpleural derecho; TSS: 5 . Su PM resultó positiva. Recibió tratamiento con meropenem, cloroquina, metilprednisolona y enoxaparina. El $\mathrm{PaFiO}_{2}$ se mantuvo siempre mayor a 300. Evolucionó favorablemente y salió de alta a los 13 días.

\section{Caso 8}

Varón de 66 años, militar en retiro, con antecedentes de HTA y cáncer de próstata operado. Refería 10 días de tos, mialgias, malestar general y fiebre, y 3 días de diarrea, cansancio e hiporexia. Dos pruebas serológicas negativas. Ingresó con SatO2 97\%, con PCR normal, dímero D elevado y linfopenia. La TCT mostró pequeñas áreas, algunas redondeadas, en vidrio deslustrado en la región subpleural de ambos lóbulos inferiores; TSS: 2. Inició tratamiento con hidroxicloroquina, azitromicina, ceftriaxona y 2 dosis de metilprednisolona. La PM resultó positiva. Al cuarto día de hospitalización presentó fiebre en picos y empeoramiento del estado general. Nueva TCT reveló mayor extensión de las áreas en vidrio deslustrado hacia las regiones apicales de los lóbulos inferiores y base del lóbulo superior izquierdo. Se rotó a meropenem y reinició metilprednisolona con evolución favorable. Fue dado de alta a los 12 días.

\section{Caso 9}

Mujer de 32 años, militar en actividad, con PM positiva (contacto de hermano positivo). Acudió tras cinco días del resultado y se hospitalizó debido a problema social. Al examen físico con $\mathrm{SatO}_{2} 98 \%$ sin soporte de oxígeno. La TCT reveló pequeñas áreas múltiples de consolidación en el lóbulo inferior derecho; TSS: 2. Recibió ceftriaxona y cloroquina por 7 y 10 días respectivamente. Alta tras 14 días de hospitalización.

\section{DISCUSIÓN}

La valoración inicial de todos los pacientes incluyó tomografía de tórax sin contraste. Todos ingresaron con procesos neumónicos, de patrones característicos de COVID-19, como el vidrio deslustrado, áreas de consolidación, empedrado desordenado, engrosamientos subpleurales y peribronquiales (Figura 1); incluso algunos pacientes, con pruebas serológicas y/o moleculares negativas al momento de la hospitalización. Existe evidencia que señala que la TCT sin contraste tiene una sensibilidad superior a estas pruebas, sobre todo en fases tempranas ${ }^{[3,4]}$. Esto nos habría permitido hospitalizar y tratar a pacientes antes de su empeoramiento clínico, como los casos 5, 6, 7 y 8 . Sin embargo, la TCT del caso 2 con TSS 13, pese a la edad de la paciente, tuvo mejoría clínica en las dos primeras semanas, pero posteriormente se complicó y falleció.

Por otro lado, la valoración de la severidad tomográfica inicial (con TSS) podría predecir la evolución clínica que tendría un paciente; lo cual fue reportado en un estudio realizado en China, que incluyó 270 pacientes ${ }^{[12]}$; aunque no ha sido el objetivo del estudio comprobar ello; pero se observó en el primer y segundo caso con TSS elevado, en la evolución fallecieron. 
Tabla 1. Características clínicas y de laboratorio, así como el tratamiento de los pacientes de la serie al ingreso hospitalario

\begin{tabular}{|c|c|c|c|c|c|c|c|c|c|}
\hline $\begin{array}{l}\text { Características } \\
\text { de los casos }\end{array}$ & Caso 1 & Caso 2 & Caso 3 & Caso 4 & Caso 5 & Caso 6 & Caso 7 & Caso 8 & Caso 9 \\
\hline Edad (años) & 91 & 68 & 94 & 46 & 44 & 30 & 63 & 66 & 32 \\
\hline Sexo & $\mathrm{F}$ & $\mathrm{F}$ & M & M & M & M & $\mathrm{F}$ & M & $\mathrm{F}$ \\
\hline $\begin{array}{l}\text { Toma de } \\
\text { muestra }\end{array}$ & $\begin{array}{l}\text { Al ingreso } \\
\text { y } 20 \text { días } \\
\text { después de } \\
\text { admisión }\end{array}$ & $\begin{array}{l}2 \text { días antes } \\
\text { del ingreso }\end{array}$ & Al ingreso & Al ingreso & $\begin{array}{l}1 \text { día antes } \\
\text { Ingreso }\end{array}$ & Al ingreso & Al ingreso & $\begin{array}{l}10 \text { y } 4 \text { días } \\
\text { antes del } \\
\text { ingreso y al } \\
\text { ingreso }\end{array}$ & $\begin{array}{l}5 \text { días antes } \\
\text { Ingreso }\end{array}$ \\
\hline $\begin{array}{l}\text { Tiempo de } \\
\text { enfermedad }\end{array}$ & 3 días & 7 días & 7 días & 7 días & 4 días & 4 días & 4 días & 10 días & 0 \\
\hline $\begin{array}{l}\text { Síntomas de } \\
\text { inicio }\end{array}$ & $\begin{array}{l}\text { Tos seca, } \\
\text { disnea }\end{array}$ & $\begin{array}{l}\text { Tos, fiebre, } \\
\text { malestar, } \\
\text { escalofríos, } \\
\text { vómitos, } \\
\text { diarrea }\end{array}$ & $\begin{array}{l}\text { Dorsalgia, } \\
\text { lumbalgia, } \\
\text { dolor } \\
\text { torácico }\end{array}$ & $\begin{array}{l}\text { Fiebre, } \\
\text { odinofagia, } \\
\text { cefalea e } \\
\text { hiporexia }\end{array}$ & $\begin{array}{c}\text { Fiebre, } \\
\text { odinofagia, } \\
\text { mialgias, disnea }\end{array}$ & $\begin{array}{l}\text { Fiebre, tos } \\
\text { seca, disnea }\end{array}$ & $\begin{array}{l}\text { Odinofagia, } \\
\text { tos, } \\
\text { dificultad } \\
\text { respiratoria, } \\
\text { dolor } \\
\text { torácico }\end{array}$ & $\begin{array}{c}\text { Tos, mialgias, } \\
\text { malestar } \\
\text { general, } \\
\text { fiebre, } \\
\text { hiporexia, } \\
\text { diarrea }\end{array}$ & Asintomática \\
\hline Antecedentes & $\begin{array}{l}\text { Demencia } \\
\text { multiinfarto, } \\
\text { HTA, fibrosis } \\
\text { pulmonar }\end{array}$ & $\begin{array}{l}\text { HTA, hipo- } \\
\text { tiroidismo }\end{array}$ & $\begin{array}{l}\text { HTA, NM } \\
\text { próstata } \\
\text { fibrilación } \\
\text { auricular }\end{array}$ & Ninguno & HTA, sobrepeso & $\begin{array}{l}\text { Trisomía 21, } \\
\text { obesidad }\end{array}$ & DM 2 & $\begin{array}{l}\text { HTA, NM } \\
\text { próstata } \\
\text { (operado) }\end{array}$ & Ninguno \\
\hline $\begin{array}{l}\text { Leucocitos } \\
\text { (x 103/uL) }\end{array}$ & 2,27 & 6,68 & 6,54 & 18,70 & 4,53 & 6,88 & 6,99 & 5,90 & 4,01 \\
\hline $\begin{array}{l}\text { Linfocitos } \\
\left.\text { (x } 10^{3} / \mathrm{uL}\right)\end{array}$ & 1,07 & 1,16 & 0,62 & 0,36 & 0,70 & 0,71 & 2,15 & 2,10 & 0,85 \\
\hline $\begin{array}{l}\text { Dímero D } \\
\text { (ug/mL) }\end{array}$ & 1,00 & 0,87 & 1,03 & 0,75 & 0,55 & 1,50 & 0,65 & 1,83 & 1,04 \\
\hline $\begin{array}{l}\mathrm{PO}_{2} \\
(\mathrm{mmHg})\end{array}$ & 80,9 & 74,5 & 71,4 & 63,0 & 68,7 & 78,0 & 70,0 & 103,8 & 89,1 \\
\hline $\mathrm{PaFi}$ & 161,8 & 240,3 & 204,0 & 211,0 & 208,0 & 281,0 & 333,0 & 494,0 & $>300$ \\
\hline $\begin{array}{l}\text { Proteína C } \\
\text { reactiva } \\
\text { (mg/dL) }\end{array}$ & 0,2 & 78,8 & 125,4 & 365,0 & 143,0 & 46,0 & 33,0 & 3,0 & 4,8 \\
\hline $\begin{array}{l}\text { Ferritina } \\
\text { (ng/mL) }\end{array}$ & 334,6 & 2000,0 & & 802,0 & 1701,0 & & & 147,64 & 502,0 \\
\hline $\begin{array}{l}\text { IL-6 } \\
\text { (pg/mL) }\end{array}$ & & & & & 43 & & & & \\
\hline $\begin{array}{l}\text { RT-PCR } \\
\text { (prueba } \\
\text { molecular) }\end{array}$ & Positivo & Positivo & Negativo & Positivo & Positivo & Positivo & Positivo & Positivo & Positivo \\
\hline $\begin{array}{l}\text { Prueba } \\
\text { serológica } \\
\text { IgM/IgG }\end{array}$ & Negativo & Positiva & Negativo & Positivo & & & & Negativas & Positivo \\
\hline Evolución & Fallecida & Fallecida & Fallecido & $\begin{array}{c}\text { Alta } \\
\text { estancia 20d }\end{array}$ & $\begin{array}{c}\text { Alta } \\
\text { estancia } 18 d\end{array}$ & $\begin{array}{l}\text { Alojamiento } \\
\text { Procede de } \\
\text { Arequipa }\end{array}$ & $\begin{array}{c}\text { Alta } \\
\text { estancia 13d }\end{array}$ & $\begin{array}{c}\text { Alta } \\
\text { estancia 17d }\end{array}$ & $\begin{array}{l}\text { Alta } \\
\text { estancia } \\
14 d\end{array}$ \\
\hline $\begin{array}{l}\text { Tratamiento } \\
\text { farmacológico }\end{array}$ & $\begin{array}{c}\text { Ceftazidima } \\
\text { Enoxaparina, } \\
\text { Hidroxicloro- } \\
\text { quina, }\end{array}$ & $\begin{array}{c}\text { Piperacilina / } \\
\text { Tazobactam, } \\
\text { Enoxaparina, } \\
\text { Metilpredni- } \\
\text { solona }\end{array}$ & $\begin{array}{l}\text { Ceftriaxona } \\
\text { Azitromicina } \\
\text { Enoxaparina }\end{array}$ & $\begin{array}{l}\text { Cloroquina } \\
\text { Azitromicina } \\
\text { Meropenem } \\
\text { Vancomicina } \\
\text { Metilpredni- } \\
\text { solona } \\
\text { Enoxaparina }\end{array}$ & $\begin{array}{l}\text { Hidroxi- } \\
\text { cloroquina } \\
\text { Azitromicina } \\
\text { Meropenem } \\
\text { Linezolid } \\
\left.\text { Tocilizumab ( } 3^{\circ} \mathrm{d}\right) \\
\text { Filgrastim } \\
\text { Metilpredni- } \\
\text { solona } \\
\text { Enoxaparina }\end{array}$ & $\begin{array}{l}\text { Hidroxi- } \\
\text { cloroquina } \\
\text { Azitromicina } \\
\text { Ceftriaxona } \\
\text { Metilpred- } \\
\text { nisolona } \\
\text { Enoxaparina }\end{array}$ & $\begin{array}{l}\text { Cloroquina } \\
\text { Meropenem } \\
\text { Metilpredni- } \\
\text { solona } \\
\text { Enoxaparina }\end{array}$ & $\begin{array}{l}\text { Cloroquina } \\
\text { Azitromicina } \\
\text { Meropenem } \\
\text { Vancomicina } \\
\text { Metilpredni- } \\
\text { solona } \\
\text { Enoxaparina }\end{array}$ & $\begin{array}{c}\text { Paracetamol } \\
\text { Cloroquina } \\
\left(6^{\circ} \mathrm{d}\right) \\
\text { Ceftriaxona }\end{array}$ \\
\hline Oxigenoterapia & $\begin{array}{l}\text { CBN, MV } \\
50 \%\end{array}$ & CBN, MR & CBN, MR & MV 35\% & MV $50 \% 3^{\circ} \mathrm{d}$ & $\begin{array}{l}\text { CBN, MV } \\
50 \%\end{array}$ & $\begin{array}{l}\text { CBN hasta } \\
\text { el } 5^{\circ} \text { día } \\
\text { luego } \mathrm{O}_{2} \\
\text { ambiental }\end{array}$ & $\begin{array}{l}\text { Ambiental, } \\
\text { CBN a } 2 \text { lpm }\end{array}$ & $\operatorname{Sin} \mathrm{O}_{2}$ \\
\hline
\end{tabular}

$\mathrm{O}_{2}$ : Oxigeno; ${ }^{\circ}$ : días después del ingreso

CBN: cánula binasal; MV: máscara de Venturi; MR: máscara de reservorio 
El enfoque inicial del paciente considera factores de riesgo, como la edad avanzada. En Perú, la letalidad llega a 12,4\% en mayores de 60 años (desde 1,35\% en pacientes de 30 a 59 años) ${ }^{[2]}$. En nuestra serie, los tres primeros casos, mayores de 60 años con TSS de mayor/igual a 8, fallecieron. Contrariamente, la paciente del caso 7, siendo mayor a 60 años y con diabetes mellitus, evolucionó favorablemente, pudiendo atribuirse al TSS bajo que presentó al ingreso (Tabla 1).

A diferencia de otras latitudes, uno de los factores de riesgo de mayor gravedad en nuestro medio fue la obesidad ${ }^{[2]}$. Esto se vería reflejado en el caso 5 que, pese a ser joven, con una TCT cuyo TSS fue 8 a su ingreso, presentó una rápida evolución desfavorable; pero que pudo recuperarse, con probable buena respuesta al antagonista de la interleucina 6 , y ser dado de alta.

También nos encontramos con pacientes asintomáticos con neumonía por TCT (caso 9). Si bien se ha documentado que la evolución de estos casos es variable, se considera que podrían ser vectores de contagio de la enfermedad ${ }^{[13]}$, lo que hace importante su identificación y aislamiento, en especial en aquellos que interactuarán con gran cantidad de personas, como es el personal militar.

En conclusión, los casos presentados muestran pacientes adultos jóvenes y de edad avanzada, con presentación clínica diversa y antecedentes patológicos particulares, en algunos casos bien definidos como factores de riesgo; todos con compromiso pulmonar en diverso grado evidenciado por la TCT y graduado mediante el TSS. Consideramos que la clínica aunada a la comorbilidad asociada y un TSS elevado puede tener un desenlace desfavorable.

Contribuciones de autoría: todos los autores han participado en la concepción, redacción y aprobación de la versión final.

Potenciales conflictos de intereses: los autores declaran no tener conflictos de intereses.

Fuente de financiamiento: autofinanciado.

\section{ORCID:}

Ursula Cáceres-Bernaola: https://orcid.org/0000-0001-5057-1651 Claudia Becerra-Núñez: https://orcid.org/0000-0002-6799-6100 Sabina Mendívil-Tuchía de Tai: https://orcid.org/0000-0002-7796-9376 Jorge Ravelo-Hernández: https://orcid.org/0000-0001-9179-3541 Edwin Quispe-Ayuque: https://orcid.org/0000-0002-0070-822 $\underline{3}$

\section{REFERENCIAS BIBLIOGRÁFICAS}

1. Wu Z, McGoogan JM. Characteristics of and Important Lessons From the Coronavirus Disease 2019 (COVID-19) Outbreak in China: Summary of a Report of 72314 Cases From the Chinese Center for Disease Control and Prevention. JAMA. 2020;323(13):1239. doi: 10.1001/jama.2020.2648.

2. CDC-MINSA. Análisis Epidemiológico de la Situación Actual de COVID-19 en el Perú, basado en la información de la Vigilancia Epidemiológica y la Investigación de Campo [Internet]. CDC-MINSA; 2020 [citado 7 junio del 2020]. Disponible en: https://www.dge. gob.pe/portal/docs/tools/coronavirus/analisiscoronavirus080520. pdf

3. Fang $\mathrm{Y}$, Zhang $\mathrm{H}$, Xie J, Lin $\mathrm{M}$, Ying L, Pang $\mathrm{P}$, et al. Sensitivity of Chest CT for COVID-19: Comparison to RT-PCR. Radiology. 2020;296(2):E115-7. doi: 10.1148/radiol.2020200432.

4. Ai T, Yang Z, Hou H, Zhan C, Chen C, Lv W, et al. Correlation of Chest CT and RT-PCR Testing for Coronavirus Disease 2019 (COVID-19) in China: A Report of 1014 Cases. Radiology. 2020;296(2):E32-40. doi: 10.1148/radiol.2020200642.

5. Xie X, Zhong Z, Zhao W, Zheng C, Wang F, Liu J. Chest CT for Typical Coronavirus Disease 2019 (COVID-19) Pneumonia: Relationship to Negative RT-PCR Testing. Radiology. 2020;296(2):E41-5. doi: 10.1148/radiol.2020200343

6. Yang W, Sirajuddin A, Zhang X, Liu G, Teng Z, Zhao S, et al. The role of imaging in 2019 novel coronavirus pneumonia (COVID-19). Eu Radiol. 2020;30(9):4874-82. doi: 10.1007/s00330-020-06827-4.

7. Chung $M$, Bernheim A, Mei X, Zhang N, Huang $M$, Zeng $X$, et al. CT Imaging Features of 2019 Novel Coronavirus (2019-nCoV). Radiology. 2020;295(1):202-7. doi: 10.1148/radiol.2020200230.

8. Li K, Fang Y, Li W, Pan C, Qin P, Zhong Y, et al. CT image visual quantitative evaluation and clinical classification of coronavirus disease (COVID-19). Eur Radiol. 2020;30(8):4407-16. doi: 10.1007/ s00330-020-06817-6.

9. Wang $Y$, Dong $C$, Hu $Y$, Li C, Ren $Q$, Zhang $X$, et al. Temporal Changes of CT Findings in 90 Patients with COVID-19 Pneumonia: A Longitudinal Study. Radiology. 2020;296(2):E55-64. doi:10.1148/ radiol.2020200843.

10. Raoufi M, Safavi Naini SAA, Azizan Z, Jafar Zade F, Shojaeian F, Ghanbari Boroujeni M, et al. Correlation between Chest Computed Tomography Scan Findings and Mortality of COVID-19 Cases; a Cross sectional Study. Arch Acad Emerg Med. 2020;8(1).

11. Yuan M, Yin W, Tao Z, Tan W, Hu Y. Association of radiologic findings with mortality of patients infected with 2019 novel coronavirus in Wuhan, China. PLOS ONE. 2020;15(3):e0230548. doi: 10.1371/ journal.pone. 0230548 .

12. Lu X, Gong W, Peng Z, Zeng F, Liu F. High Resolution CT Imaging Dynamic Follow-Up Study of Novel Coronavirus Pneumonia. Front Med. 2020;7. doi: 10.3389/fmed.2020.00168.

13. Meng $\mathrm{H}$, Xiong $\mathrm{R}$, He R, Lin $\mathrm{W}$, Hao $\mathrm{B}$, Zhang $\mathrm{L}$, et al. CT imaging and clinical course of asymptomatic cases with COVID-19 pneumonia at admission in Wuhan, China. J Infect. 2020;81(1):e33-9. doi: 10.1016/j.jinf.2020.04.004. 